\title{
Main Trends of E-Government Development
}

The following section will illustrate the most important and remarkable changes of the global eGovernment which we found during the past five years in our e-Government ranking survey.

E-Government and Public Administration Reform: Many governments, especially in developing countries, started changing their awareness about the role of ICT in the public sector. Governments have become aware that it is not enough to introduce ICT to their existing internal processes, but to use ICT to assist the reengineering process in government organization concurrently with some other e-government initiatives.

Agent-Centric to Citizen-Centric: Governments invested huge capital into infrastructure when they started e-government programs. Changing from supply based solutions to meeting the demand of citizens, governments are gradually shifting to provision of e-services which are the most convenient for citizens and other stakeholders in their society.

E-Government to E-Governance: There is a gradual change in the way governments interact with their citizens: from merely providing services, governments have established virtual-spaces for citizen to have their voice. In this way, citizens have been given the opportunity to participate in policy making by using ICT. Strengthening of democratic processes by the means of ICT brought to the forefront the importance of electronic municipal services. The efforts for decentralization in e-Government strategies can be clearly viewed to date in countries with strong democratic culture where municipalities enjoy considerable independence. The shift from administration to social and political services and as a consequence the shift from federal to local e-government might be considered as a transition from e-government to e-governance.

The new role of government CIO: Concurrently with the development of e-government, CIO in the public sector has been given more and more duties. In the past their main responsibility was information technology and their position was information technology director. However, nowadays their concerns include not only technology but also social and administrative work. As a result, many governments in the world change the content and method of training and selecting $\mathrm{CIO}$ in the public sector to be more comprehensive.

\section{Main Trends of e-Government by Indicators}

\section{Network Preparedness}

Regarding network preparedness, the major and basic foundation for implementing e-government such as Internet users, Broadband users, Cellular phone users, and PC users have been well established, while an increasing number of countries have already reached the top level of the world.

\section{Required Interface-Functioning Applications}

The availability of user-friendly and secure electronic services is the ultimate goal of e-Government initiatives. The first strategies of electronic services delivery were guided by the knowledge of the functions and areas of responsibility of government agencies and were focused on online presence with gradual enhancement of the services. With the shift to user-oriented strategies to service delivery in the last years, many countries are catching up with the leaders and have visible results in offering much more diverse, advanced and comprehensive electronic services through one-stop-shop portals. To ensure usability of offered services and trust to e-Governance, the countries are putting their efforts to ensure secured transactions by adopting necessary legislation and introducing various security features. The only service that is lagging behind in its implementation is e-Voting, hampered by unavailability of proper legislation and security challenges. 


\section{Management Optimization}

All governments realize that ICT is able to help them streamline their processes and optimize the productivity of their ministries and departments. However, not all governments emphasize an integrated and uniformed effort. In this category, we measure the government's computerization and ICT integration attainment, quantifying the government's efforts in these areas.

\section{Homepage}

The national portal is the foundation of e-government and a basic interface for stakeholders to access government in an electronic way. Most of the countries in our sample have established their portal very early and achieved a certain level already. For this year, a new pattern and set of indicators were employed in order to test the new generation of national portal.

Since 2003, a new wave of web-based services has been launched with a creative idea and obtained a fruitful success undoubtedly, for example Wikipedia, Blog and so on. These e-services based on the concept of the user as a producer of content, contacts, feedback and even applications, is generally known as the stream of Web 2.0. Currently, the concept of Web 2.0 is being adopted in public sector more and more. For year 2008, Singapore, USA and Korea made a big progress on their national portal undoubtedly. Rapid improvement of HP without substantial operations is the concerned issue.

\section{Chief Information Officers (CIOs) in Government}

CIO (Chief Information Officer) in government is seen to be one of the key factors to the success of e-government. Therefore, Waseda Institute of e-government had included a set of CIO indicators since the first egovernment ranking in 2005. As awareness of the important roles of CIO is increasing, most of our sample countries designated CIOs (or equivalent titles) responsible for e-government implementation. They also have programs for CIO development, bodies for supporting $\mathrm{CIO}$ and framework for CIO functions in certain levels. As a result, the differentiation regarding $\mathrm{CIO}$ between the countries is smaller and smaller.

In fact, the indicators of $\mathrm{CIO}$ in government are not as suitable as they were five years ago. These indicators can not sufficiently cover and evaluate the new roles and activities in national level and sub-national level of CIO. Therefore, the improvement of these indicators is required, based on the principle of following, concretizing and extending the previous indicator. Compared to the last rankings, all the names of indicators and sub-indicators have been changed and the checklist for each sub-indicator, based on definitions from the last period are made that provides a higher degree of differentiation among surveyed countries(economies).

In coming 5 years or so, the majority is expected to appoint legally-defined CIOs at all levels and establish training, consulting, and studying organizations as some leading countries already do. And the leaders will continue benchmarking, learning best practices, and then developing their $\mathrm{CIO}$ roles, leading to realization of a new type of organizational structure where CIO substantially plays key roles in both leading and sustaining all kinds of public services.

\section{e-Government Promotion}

More nations are increasing their efforts in egovernment promotional activities. The United States is still in first place for its e-Government Promotion Activities, sharing this position with Canada, Singapore and Japan, which have improved their scores for this field, compared to last year. Korea has dropped from second place to fifth. In a similar way, Finland

and Australia have descended from second place to eighth and tenth respectively. Four countries (Sweden, Norway, Hong Kong and Taiwan) have improved from last year to be part of the top ten for Promotion Activities.

\section{Recommendations}

Although recently the world has seen the significant development in delivering the public services via Internet since the beginning of e-Government era, there are some challenges that governments would have to address in earnest for the next few years.

Most of the surveyed countries have by and large made progress through building basic ICT infrastructures, establishing integrated government portals, extending the on-line availability of governmental services, and training and assigning CIOs with the aim of realizing IT-enabled public administration reform. While enhanced citizen participation should be the core objective of e-Government initiatives. Therefore, a number of countries are facing a major turning point in its further implementation in the real sense. 
One of the most required efforts is to let e-Government go into citizens' hands. After making the national e-Government ready, it must spread toward lower levels such as e-Municipality, facing several inherent problems in implementation: limitation of budget, necessity of horizontal and vertical collaboration and standardization, and human resource development to initiate and maintain the local e-Governments.

In another respect, only a few countries have recorded satisfying use of their online services which implies that "marketing" of online services is further required. Hence, the policy-makers should pay attention not only to mention citizen needs assessment but marketcentric products (online services) development, promotion and even enrichment of user experience through continuous improvement based on the user participation. Additionally, cyber laws, authentication systems' comprehensiveness, and adoption of Web 2.0 paradigm which is the technology promoting citizens to use online services, will assist to shape the next stage of eGovernment.

To make the above-mentioned change happen in effect, however, management optimization, if not organizational transformation, has been and still is a core issue. Even the development and assignment of CIOs is far from enough. They are required to obtain the prominent competencies such as transformational leadership or sensitivity and responsiveness to external environment. Moreover, structures and cultures of governmental organizations should follow the requirement for better governance with openness, transparency, and accountability to citizens. Governments must put themselves and ICT last, while putting their citizens first, to make the most of ICT and governments for good governance. In the near future both WEB2.0 and Mobile government will be the hottest issues in e-Government 


\section{Annex}

\begin{tabular}{ll}
\hline Research Name & 5th Waseda University International e-Government Ranking 2009 \\
\hline Research Organization & Waseda University Institute of e-Government \\
& To conduct a research on the status and development of e-government in the world, and to rank the surveyed \\
& countries based on the various criteria for an ideal e-Government. \\
Research Method & This research was conducted by the staff of Waseda University Institute of e-Government and researchers of \\
& Waseda University Graduate School of Global Information and Telecommunications Studies, under the guidance \\
& of Professor Toshio Obi, Director, Institute of e-Government. Along with the assessment of relevant web pages, \\
& the Waseda University Institute of E-Government carried out several activities during the year: organized e- \\
& government experts' conferences and invited them as researchers. Members of the Institute attended international \\
& e-Government conferences, and visited governments and think-tanks in major countries. In addition, references of \\
& international organizations such as APEC, OECD, the International Telecommunications Union (ITU), the World \\
& Bank and World Economic Forum, were uesed. A total of 34 countries or economies served as the sampling \\
& units for this research, which includes: Australia, Belgium, Brazil, Brunei, Canada, China, Chile, Fiji, Finland, \\
& France, Germany, Hong Kong, India. Indonesia, Italy, Japan, Korea, Malaysia, Mexico, Netherlands, New Zealand, \\
& Norway, Peru, Philippines, Russia, Singapore, South Africa, Spain, Sweden, Taiwan, Thailand,, United Kingdom, \\
the United States, Vietnam The research was conducted throughout year 2008, in three periods, from April to July \\
for preparation, from August to November for research proceedings, and whole December and January for review \\
and finalization. \\
A total of 28 indicators including more than 100 parameters were used to evaluate six fields that constitute an ideal \\
e-Government. Some parameters were measured by using 5-points scale, while rest of them were measured by \\
check list methodology. Each sector has been tested whether its reliability is significant or not, in both quantitative \\
and qualitative measurement. \\
6 sectors, 28 indicators (including 115 parameters)
\end{tabular}

Table 1

5th Waseda University International ranking on e-Government 2009

\begin{tabular}{clc}
\hline Rank & Country & Weighted Score \\
\hline 1 & Singapore & 92.89 \\
2 & USA & 89.31 \\
3 & Sweden & 86.94 \\
4 & UK & 85.45 \\
5 & Japan & 82.30 \\
& Korea & 82.30 \\
7 & Canada & 80.24 \\
8 & Taiwan & 78.69 \\
9 & Finland & 76.02 \\
10 & Germany & 75.30 \\
& Italy & 75.30 \\
12 & Norway & 73.84 \\
13 & Australia & 73.60 \\
14 & HongKong & 71.86 \\
15 & Belgium & 71.26 \\
16 & Spain & 70.77 \\
17 & France & 70.61 \\
\hline
\end{tabular}

\begin{tabular}{clc}
\hline Rank & Country & Weighted Score \\
\hline 18 & Netherlands & 68.88 \\
19 & New Zealand & 68.58 \\
20 & Mexico & 64.68 \\
21 & Thailand & 64.51 \\
22 & Malaysia & 63.38 \\
23 & Indonesia & 62.02 \\
24 & India & 60.89 \\
25 & South Africa & 55.45 \\
26 & China & 53.25 \\
27 & Philippines & 50.81 \\
28 & Chile & 47.11 \\
29 & Russia & 41.66 \\
30 & Brazil & 41.28 \\
31 & Vietnam & 40.77 \\
32 & Peru & 38.26 \\
33 & Brunei & 33.59 \\
34 & Fiji & 26.02 \\
\hline
\end{tabular}


Table 2

Dimensions and Indicators

\begin{tabular}{ll}
\hline Sectors & Items \\
\hline 1. Network Preparedness & 1-1 Internet users 1-2 Broadband users 1-3 Digital mobile users 1-4 PC users \\
2. Required Interface-Functioning Applications & 2-1 Cyber Laws 2-2 e-tender system 2-3 e-tax system 2-4 e-payment system 2-5 e- \\
& voting system 2-6 Social Security Services 2-7 Civil Registration Services 2-8 Consular \\
& Services 2-9 Labor Related Services \\
& 3-1 Optimization Awareness 3-2 Integrated Enterprise Architecture 3-3 Administrative \\
3. Management Optimization & and budgetary systems \\
& 4-1 Navigation 4-2 Interactivity 4-3 Interface 4-4 Technical \\
4. National Portals & 5-1 CIO Presence 5-2 CIO Development Programs 5-3 CIO Organizations 5-4 CIO \\
5. CIO in Government & Mandate \\
& 6-1 Legal Mechanism 6-2 Enabling Mechanism 6-3 Support Mechanism 6-4 Assessment \\
6. e-Government Promotion & Mechanism \\
\hline
\end{tabular}

Table 3

Top 10 Ranking for Each Sector

\begin{aligned} & \hline $\begin{array}{c}\text { Interface Function and } \\ \text { Applications }\end{array} \\ &$\hline 1 USA \\ & 2 Singapore \\ & 3 Canada \\ & 4 France \\ & 5 Australia \\ & 6 UK \\ & 7 Japan \\ & 8 New Zealand \\ & 9 Belgium \\ & 10 Spain \\ & \hline\end{aligned}

\begin{aligned} & \hline Mgt. Optimization \\ & \hline 1 Singapore \\ & 2 Germany \\ & 3 Taiwan \\ & 4 Italy \\ & 5 France \\ & 6 Spain \\ & 7 Japan \\ & 8 Sweden \\ & 9 Finland \\ & 10 Thailand \\ & \hline\end{aligned}

\begin{aligned} & \hline \multicolumn{2}{c}{ National Portal } \\ & \hline 1 Singapore \\ & 2 USA \\ & 3 Korea \\ & 4 Malaysia \\ & 5 Sweden \\ & 6 Canada \\ & 7 Finland \\ & 8 Hong Kong \\ & 9 UK \\ & 10 Taiwan \\ & \hline\end{aligned}

\begin{aligned} & \hline CIO in Government \\ & \hline 1 USA \\ & 2 Korea \\ & 3 Singapore \\ & 4 Japan \\ & 5 UK \\ & 6 Thailand \\ & 7 Canada \\ & 8 Germany \\ & 9 Malaysia \\ & 10 Taiwan \\ & \hline\end{aligned}

\begin{aligned} & \hline e-Gov Promotion \\ & \hline 1 Sweden \\ & 2 Japan \\ & 3 Korea \\ & 4 UK \\ & 5 USA \\ & 6 Canada \\ & 7 Singapore \\ & 8 Australia \\ & 9 Mexico \\ & 10 Norway \\ & \hline\end{aligned}

Table 4

Comparison on the 1st, 2nd, 3rd, 4th and 5th ranking results

\begin{tabular}{|c|c|c|c|c|c|c|c|c|c|}
\hline & 2009 & & 2008 & & 2007 & & 2006 & & 2005 \\
\hline 1 & Singapore & 1 & USA & 1 & USA & 1 & USA & 1 & USA \\
\hline 2 & USA & 2 & Singapore & 2 & Singapore & 2 & Canada & 2 & Canada \\
\hline 3 & Sweden & 3 & Canada & 3 & Canada & 3 & Singapore & 3 & Singapore \\
\hline 4 & U.K & 4 & Korea & 4 & Japan & 4 & Japan & 4 & Finland \\
\hline 5 & Japan & 5 & Japan & 4 & Korea & 5 & Korea & 5 & Sweden \\
\hline 5 & Korea & 6 & Hong Kong & 6 & Australia & 6 & Germany & 6 & Australia \\
\hline 7 & Canada & 7 & Australia & 7 & Finland & 7 & Taiwan & 7 & Japan \\
\hline 8 & Taiwan & 8 & Finland & 8 & Taiwan & 8 & Australia & 8 & Hong Kong \\
\hline 9 & Finland & 9 & Sweden & 9 & UK & 9 & UK & 9 & Malaysia \\
\hline 10 & Germany Italy & 9 & Taiwan & 10 & Sweden & 10 & Finland & 10 & UK \\
\hline
\end{tabular}

